\title{
Teoria da Cultura do Consumo: possibilidades, limitações e caminhos em estudos de marketing no Brasil
}

\author{
LUCIANA ALVES RODAS VERA ${ }^{12}$ \\ MARLUSA DE SEVILHA GOSLING ${ }^{2}$ \\ HELENA BELINTANI SHIGAKI ${ }^{2}$ \\ Universidade Salvador (Unifacs) / Programa de Pós-Graduação em \\ Administração da Unifacs, Salvador - BA, Brasil \\ ${ }^{2}$ Universidade Federal de Minas Gerais (UFMG) / Centro de Pós-graduação e \\ Pesquisas em Administração (CEPEAD), Belo Horizonte - MG, Brasil
}

\section{Resumo}

Em uma cultura em que os consumidores passam a ser representados e compreendidos como sujeitos em busca de uma identidade reflexiva e empoderada, o tema Consumer Culture Theory ou Teoria da Cultura do Consumo (CCT) ganha relevância. Este ensaio teórico tem por objetivo a discussão sobre as possibilidades, as críticas e os caminhos dessa tradição teórica em estudos de Marketing no Brasil. Os resultados deste ensaio teórico apontam que tal abordagem tem ganhado crescente atenção no campo do comportamento do consumidor, com estudos desenvolvidos em vários sentidos, como padrões sócio-históricos de consumo, culturas demercado, identidade do consumidor e apropriações do uso de mídias. Igualmente, notase que a CCT apresenta muitas possibilidades em pesquisa de marketing, tanto no contexto brasileiro quanto estrangeiro e que suas poucas críticas podem ser solucionadas e revertidas por meio do contexto interdisciplinar que este novo campo de estudo propõe.

Palavras-chave: Consumer Culture Theory. Cultura do Consumo. Possibilidades. Limitações. 


\title{
Consumer Culture Theory: Limitations and possibilities for marketing studies in Brazil
}

\begin{abstract}
The Consumer Culture Theory (CCT) gains relevance in a culture where consumers are represented and understood as subjects in search of a reflective and empowered identity. This theoretical essay presents a brief review of the literature on CCT and aims to discuss the possibilities and limitations of this theoretical tradition in marketing studies in Brazil. The conclusion of this work is that the consumer culture theory has gained increasing attention in the field of consumer behavior, and there are studies carried out on patterns of socio-historical consumption, market culture, consumer identity, and media use appropriation. Also, it is perceived that the CCT has many possibilities in marketing research, both in the Brazilian and international contexts. Finally the few criticisms of the CCT can be addressed and reversed when observed based on the interdisciplinary context that this new field of study proposes.
\end{abstract}

KeYwords: Consumer Culture Theory. Consumer Culture. Possibilities. Limitations.

\section{Teoría de la Cultura del Consumo: posibilidades, limitaciones y caminos en estudios de marketing en Brasil}

\section{Resumen}

En una cultura en la que los consumidores pasan a ser representados y comprendidos como sujetos en busca de una identidad reflexiva y empoderada, el tema Consumer Culture Theory o Teoría de la Cultura del Consumo (CCT) adquiere relevancia. Este ensayo teórico tiene como objetivo la discusión sobre las posibilidades, las críticas y los caminos de esa tradición teórica en estudios de Marketing en Brasil. Los resultados de este ensayo teórico señalan que dicho abordaje ha obtenido una creciente atención en el campo del comportamiento del consumidor, con estudios desarrollados desde diversos enfoques, como estándares socio-históricos de consumo, culturas de mercado, identidad del consumidor y apropiaciones del uso de los medios. Igualmente, se nota que la CCT presenta muchas posibilidades en investigación de marketing, tanto en el contexto brasileño como extranjero y que sus pocas críticas pueden solucionarse y revertirse por medio del contexto interdisciplinario que este nuevo campo de estudio propone.

Palabras clave: Consumer Culture Theory. Cultura del consumo. Posibilidades. Limitaciones. 


\section{Introdução}

O comportamento do consumidor diz respeito a uma área de estudo do Marketing que tem recebido crescente interesse da Academia nos últimos 50 anos, devido ao aumento da concorrência e do fenômeno da globalização, o que indica desafios para as empresas na manutenção e conquista de mercados (CASOTTI e SUAREZ, 2016). Nota-se que, ao longo desse período, três perspectivas ganharam destaque dentro desse escopo: a Teoria da Decisão Comportamental (TDC), o modelo racional do Processamento de Informação (MPI) e a Consumer Culture Theory (CCT).

A TDC, de acordo com as autoras supracitadas, é voltada para aspectos racionais do consumo e tem como base fundamentos da psicologia cognitivista e da economia para elucidar temas como processo de decisão, heurísticas e vieses, escolha intertemporal e julgamento diante de incerteza.

A perspectiva baseada no MPI enfatiza os processos de informação para tomada de decisão e complementa abordagens mais racionalistas, ao investigar aspectos menos conscientes do processo de consumo (CASOTTI e SUAREZ, 2016).

Já a CCT corresponde a uma perspectiva mais recente, que tem incentivado a investigação dos aspectos contextuais, simbólicos e experienciais de consumo. É definida por Arnould e Thompson (2005) como um grupo de perspectivas teóricas que abordam as relações dinâmicas entre as ações de consumo, o mercado e os significados culturais. A visão sobre o consumo tem se movido daquela baseada na maximização da utilidade (econômica) ou no processo de aquisição (estudos de negócios) para uma visão baseada no (a) processo que permeia as relações entre a sociedade e o indivíduo, (b) nas formas de classificação social e de sistemas de comunicação, (c) nos processos de formação de identidade, de rituais e de comunidades de compra, e (d) na busca por experiências plenas existenciais (ASKEGAARD e LINNET, 2011).

O objetivo deste ensaio teórico é discutir as possibilidades da CCT, as críticas, limites e limitações feitas a ela e os caminhos possíveis dessa abordagem na pesquisa de marketing, especialmente no Brasil. A elaboração deste ensaio tem por justificativa contribuir com futuras pesquisas na área, ao sinalizar possíveis caminhos, elucidar as críticas que vêm sendo feitas, bem como tentar solucioná-las, além de mostrar a atual realidade do Brasil nesse novo campo de estudo. Igualmente, os resultados apresentados neste ensaio podem contribuir com pesquisas futuras na área por meio das questões apresentadas e das reflexões produzidas.

\section{Uma Breve Revisão da CCT e suas Possibilidades de Pesquisa}

Os estudos sob a perspectiva experiencial do consumidor não têm sua origem definida na literatura. Porém, recorre-se a Holbrook e Hirschman (1982) para marcar o início dessa discussão. Estes autores, segundo Pinto, Freitas, Resende et al. (2015), destacaram a importância de estudos nessa área, do ponto de vista dos aspectos de fantasia, sentimentos e diversão, envolvendo sonhos, emoções e prazeres. Com seu artigo, começou-se a explorar questões ligadas aos rituais de consumo e simbolismo, experiências de consumo e fantasias, o 
simbolismo dos bens e questões culturais no comportamento do consumidor (COSKUNERBALLI, 2013).

Partindo desse horizonte, ainda que se fale do estudo seminal de Holbrook e Hirschman (1982), há autores anteriores a eles que iniciaram seus estudos sobre a experiência do consumidor. Dentre eles, Pinto, Freitas, Resende et al. (2015) mencionam: Wroe Alderson (1957) e Lawrence Abbott (195-), que enfatizaram a importância da experiência no consumo, e Stanley Lebergott (1993), que buscou identificar e traçar o conceito de experiência de consumo com base em John Maynard Keynes, Alfred Marshall e Adam Smith. Além desses, trabalhos de autores como Brillat-Savarin, Paul Lazarsfeld e Ernest Dichter são apontados como pesquisas da área do comportamento do consumidor de natureza qualitativa e interpretativista por Levy (2006) e Belk (2014). Outros pesquisadores também ofereceram contribuições importantes para estudar os consumidores de maneira qualitativa, como Veblen, James, Malinowski, Geertz, Sahlins, Mead, Bateson, Douglas e Miller.

A CCT tem suas origens em um projeto chamado Consumer Behavior Odyssey, iniciado em 1985 nos Estados Unidos por um grupo de aproximadamente doze pesquisadores, a exemplo de Russell Belk, Melanie Wallendorf e John Sherry, que partiram pelos EUA em uma van para conduzir um estudo de campo etnográfico multilocalizado, com entrevistas, fotografias e filmagens (JOY e LI, 2012). Até então, à época, os principais periódicos da área de marketing eram dominados amplamente por estudos de natureza quantitativa e experimental. Um dos objetivos desse movimento era propor o desenvolvimento de estudos que fossem além dos trabalhos de caráter positivista predominante até o momento (BELK, 2014).

A ideia do projeto era desenvolver um estudo eclético e multidisciplinar que focasse no comportamento do consumidor e não no do comprador. O intuito era afastar-se do positivismo, com a pesquisa voltada para o experimento, para o survey e a estatística (BELK, 2014). Os trabalhos resultantes da Odisseia tiveram impacto no campo dos estudos do comportamento do consumidor e resultou em novos estudos.

Foi assim que Thompson (2004), em uma apresentação realizada em 2004, apresentou no Consórcio Doutoral na Universidade de Nebrasca em Portland (Oregon), pela primeira vez, o termo Consumer Culture Theory. Posteriormente, Arnould e Thompson (2005) voltaram a utilizar o termo no artigo "Consumer Culture Theory (CCT): Twenty years of research", no intuito de cunhar um nome para o conjunto de trabalhos desenvolvidos desde o começo da Odisseia. Esses autores explicam que essa tradição de pesquisa corresponde a um grupo de perspectivas teóricas que tem como abordagem as relações dinâmicas entre as ações de consumo, o mercado e os significados culturais. Mesmo representando uma pluralidade de distintas abordagens teóricas e de objetivos de pesquisa, os pesquisadores da CCT, contudo, partilham uma orientação teórica comum para o estudo da complexidade da cultura, que liga de forma programática seus respectivos esforços de investigação.

Dessa forma, a cultura passa a ser vista não mais como um "sistema homogêneo de significados compartilhados coletivamente" (PINTO, FREITAS, RESENDE et al., 2015, p. 51), mas sim como a distribuição heterogênea desses significados, a fim de compreender os grupos e suas manifestações via formações sócio-históricas (PINTO, FREITAS, RESENDE et al., 2015). Desde então, a CCT tornou-se um acrônimo utilizado e reconhecido nos principais 
periódicos da área (COVA e COVA, 2014), com visibilidade em periódicos internacionais, como Journal of Consumer Research; Journal of Marketing; European Journal of Marketing; Culture, Markets and Consumption; Journal of Consumer Culture; Journal of Marketing Research; Journal of Retailing; Journal of the Academy of Marketing; Journal of Advertising; Research in Consumer Behavior; Consumption Markets and Culture; e Journal of Consumer Behavior. Em periódicos brasileiros: Revista de Marketing (ReMark); Cadernos EBAPE. BR; Revista de Administração de Empresas (RAE); Comunicação, Mídia e Consumo; ADM. MADE; Revista Interdisciplinar de Marketing; Revista de Administração Contemporânea (RAC); Revista Eletrônica de Administração (REAd); e Revista de Negócios (MORAIS e QUINTÃO, 2016). Também em congressos nacionais e estrangeiros: Encontro da Anpad, Association for Consumer Research (ACR), American Marketing Association (AMA) e Consumer Culture Theory Conference.

A CCT explora a distribuição heterogênea de significados e a multiplicidade de grupos culturais que existem dentro do mais amplo quadro sócio-histórico da globalização e do capitalismo de mercado. Na CCT, a cultura do consumo é um construto central, concebido como um arranjo social em que as relações entre cultura vivida e recursos sociais, e entre formas significativas da vida e do simbólico e recursos materiais de que dependem, são mediadas pelo mercado (ARNOULD e THOMPSON, 2005; ARNOULD, 2006). Kozinets (2001) define a cultura do consumo como um sistema particular interligado por imagens, textos e objetos produzidos comercialmente e utilizados por grupos particulares - por intermédio da construção de práticas, identidades e significados sobrepostos e até mesmo conflitantes - para criar um senso coletivo de seus ambientes e para orientar as experiências e vidas de seus membros.

Arnould (2006) explica que a pesquisa do consumidor inspirada por esse construto refere-se geralmente a aspectos socioculturais, experienciais, simbólicos e ideológicos do consumo. Em complemento, Arnould e Thompson (2005) expõem que esta tradição de pesquisa se desenvolveu significativamente por meio de estudos empíricos interpretativistas, que analisam como manifestações particulares de cultura de consumo são constituídas, sustentadas, transformadas e moldadas por forças históricas mais amplas (como narrativas culturais, mitos e ideologias), fundamentadas em circunstâncias socioeconômicas e sistemas de mercado específicos.

Assim, tais autores definem a CCT como uma tradição de pesquisa interdisciplinar que tem conhecimento avançado sobre a cultura do consumo (em suas manifestações heterogêneas) e tem gerado conclusões empiricamente fundamentadas e inovações teóricas que são relevantes para um conjunto de disciplinas relacionadas às ciências sociais ligadas a setores gerenciais.

A tradição de pesquisa da CCT direciona-se ao estudo dos contextos de consumo para gerar novos construtos e insights teóricos, além de incentivar a investigação dos aspectos contextuais, simbólicos e experienciais de consumo que vão se desenrolando por meio de um ciclo de consumo, que inclui a aquisição, o consumo e a posse, e os processos de disposição e análise desses fenômenos, sob perspectivas teóricas micro, meso e macro (ARNOULD e THOMPSON, 2005). Em síntese, as principais questões teóricas da CCT estão organizadas em quatro estruturas de interesse, coforme ilustra o Quadro 1. 
QUADRO 1

Estruturas Comuns de Interesse Teórico

\begin{tabular}{|c|c|c|}
\hline Estrutura & Questões de interesse teórico & $\begin{array}{l}\text { Exemplos de trabalhos } \\
\text { desenvolvidos }\end{array}$ \\
\hline $\begin{array}{l}\text { Culturas de } \\
\text { mercado }\end{array}$ & $\begin{array}{l}\text { Dinâmicas socioculturais imbuídas } \\
\text { nas comunidades de marca; } \\
\text { comunidades de fãs; microculturas } \\
\text { de consumo; subculturas de } \\
\text { consumo; tribos de consumo; } \\
\text { mercado como mediador de } \\
\text { relações sociais e relacionamentos } \\
\text { sociais. }\end{array}$ & $\begin{array}{l}\text { Peñaloza e Price (1993); Celsi, Rose } \\
\text { e Leigh (1993); Kozinets (2001); } \\
\text { Kozinets (2006); Paiva, Arruda, Forte } \\
\text { et al. (2010); Leão, Vieira e Gaião } \\
\text { (2011); Cruz, Augusto, Vieira et al. } \\
\text { (2012); Henkes e Dalmoro (2015). }\end{array}$ \\
\hline $\begin{array}{l}\text { Projetos de } \\
\text { identidade do } \\
\text { consumidor }\end{array}$ & $\begin{array}{l}\text { Jogos de identidade; imagem } \\
\text { corporal e autoapresentação; } \\
\text { performance de gênero; distinções } \\
\text { simbólicas; self estendido; } \\
\text { negociação de contradições } \\
\text { culturais; dimensões experienciais } \\
\text { do consumo. }\end{array}$ & $\begin{array}{l}\text { Holbrook e Hirschman (1982); } \\
\text { Arnould e Price (1993); Carvalho } \\
\text { e Motta (2004); Belk e Yeh (2011); } \\
\text { Almeida, Froemming e Huber (2013); } \\
\text { Barboza e Ayrosa (2013); Belk (2013); } \\
\text { Aguiar e Farias (2014); Farias, Aguiar } \\
\text { e Melo (2014); Gopaldas (2014); } \\
\text { Pinto, Reale, Segabinazzi et al. (2015); } \\
\text { Cupolillo e Ayrosa (2016). }\end{array}$ \\
\hline $\begin{array}{l}\text { Padrões } \\
\text { sócio-históricos } \\
\text { de consumo }\end{array}$ & $\begin{array}{l}\text { Formação do consumo por classe, } \\
\text { etnia, gênero e outras habituais } \\
\text { categorias sociais; consumo sob } \\
\text { condições de recursos culturais } \\
\text { atenuados; institucionalização e } \\
\text { reprodução das relações de poder } \\
\text { nas hierarquias socioeconômicas; } \\
\text { anticonsumo; consumo consciente; } \\
\text { resistência ao consumo. }\end{array}$ & $\begin{array}{l}\text { Fabi, Lourenço, Silva et al. (2009); } \\
\text { Barros, Sauerbronn, Costa et al. } \\
\text { (2010); Peñaloza e Barnhart (2011); } \\
\text { Izberk-Bilgin (2012); Kraemer, } \\
\text { Silveira e Rossi (2012); Dalmoro, } \\
\text { Peñaloza e Nique (2014); Ceglia, } \\
\text { Lima, Leocádio et al. (2015); } \\
\text { Rohden, Durayski, Teixeira et al. } \\
\text { (2015); Pereira e Souza (2018). }\end{array}$ \\
\hline $\begin{array}{l}\text { Ideologias } \\
\text { do mercado } \\
\text { midiático de } \\
\text { massa e as } \\
\text { estratégias } \\
\text { interpretativas } \\
\text { dos } \\
\text { consumidores }\end{array}$ & $\begin{array}{l}\text { Representações materiais, } \\
\text { discursivas e por meio de imagens } \\
\text { das ideologias consumistas no } \\
\text { mercado; uso ativo da mídia } \\
\text { pelos consumidores e leituras } \\
\text { críticas contrárias aos códigos } \\
\text { hegemônicos; dinâmicas de } \\
\text { cooptação corporativas; influência } \\
\text { da globalização nas mídias e no } \\
\text { consumo. }\end{array}$ & $\begin{array}{l}\text { Hirschman e Thompson (1997); } \\
\text { Lawrence e Phillips (2002); Kozinets } \\
\text { e Handelman (2004); Zhao e Belk } \\
\text { (2008); Baldanza e Abreu (2010); } \\
\text { Brei, Garcia e Strehlau (2011); Barros } \\
\text { (2014); Faria e Casotti (2014). }\end{array}$ \\
\hline
\end{tabular}

Fonte: Elaborado pelos autores com base em Arnould e Thompson (2005) e Morais e Quintão (2016).

Dentre outras possibilidades de estudo, além das apresentadas no Quadro 1, Cova e Cova (2015) apontam estudos relacionados a marcas ícones baseados em estudos etnográficos, a fim de buscar a compreensão da criação de um mito convincente e de uma história que pode ajudar a resolver tensões agudas que as pessoas sentem em suas próprias vidas. O mesmo ocorre em estudos referentes ao marketing de relacionamento, em que o funcionário é convidado a ter uma experiência de um dia 'na vida do cliente' para entender as relações de poder, hierarquia e 
a variação no relacionamento, tal como satisfação, lealdade ou respeito (COVA e COVA, 2015). Outra possibilidade de estudo refere-se às comunidades de marca, em que se passa a pensar de forma holística, com foco no consumidor. Além dessas, tem se estudado mais recentemente o comportamento voluntário dos consumidores e sua necessidade em fazer parte do processo de cocriação de um serviço ou produto de uma empresa.

Assim, a CCT se dirige à dinâmica complexa existente entre: os projetos de identidade dos consumidores, a cultura popular, as estruturas de mercado, o padrão de consumo sócio-histórico emergente e as ideologias de mercado (ARNOULD e THOMPSON, 2005; ARNOULD, 2006). Ou seja, "[...] o objetivo de consumidor seria o de operar um sistema coerente de informação e classificação cultural” (PEREIRA e SOUZA, 2018, p. 133).

Nas palavras de Arnould (2006), na CCT os consumidores são compreendidos como produtores de projetos de identidade que procedem usando os recursos simbólicos e materiais oferecidos pelo mercado. Askegaard e Linnet (2011) complementaram ao afirmar que tem sido central para a CCT a representação do consumidor enquanto sujeito que busca uma identidade reflexiva e empoderada, trilhando seu caminho por intermédio da infinidade de oportunidades fornecidas pelo mercado, e muitas vezes refletindo, mediado por mensagens que o envolvem, tanto consciente quanto criticamente sobre o mercado.

Esse corpo de trabalho teoriza discursos e práticas culturais relativos à orientação e à estruturação de formas da vida sociocultural que produzem sentidos no indivíduo e no mercado (PEÑALOZA e MISH, 2011). A CCT enfatiza que os significados culturais são apenas parcialmente entendidos como uma "influência sobre" o comportamento individual. Essa tradição conceitua significado como uma reprodução de grupo, e a cultura como um campo discursivo e um conjunto de práticas improvisadas fundamentais para a formação de subjetividades e atividades dos atores.

Na perspectiva de Peñaloza e Mish (2011), os significados culturais fornecem o material subjetivo segundo o qual as pessoas interpretam-se como indivíduos e realizam a compreensão do objetivo compartilhado, tornando suas interações inteligíveis com os outros, dentro e fora dos mercados. Para as autoras, são exemplos de significados: identidades, relacionamentos, visões de mundo cosmológicas, declarações de missão da organização, histórias e mitos.

Em um estudo empregando o método desk research, Gaião, Souza e Leão (2012) propuseram uma investigação - tomando por base artigos e periódicos da área - sobre a CCT poder ser considerada já uma escola de pensamento autonôma dentro do campo de pesquisa do comportamento do consumidor. Assim, baseando-se em três critérios fundamentais, propostos e confirmados na literatura voltada para a filosofia da ciência, para qualificação de uma escola de pensamento (reconhecimento acadêmico, corpo de conhecimento e contribuições), os autores concluíram que a CCT atende aos critérios determinados, visto ser constituída por um corpo sólido de conhecimento, com temáticas e teorias características, e voltada a responder os aspectos que norteiam as atividades de marketing (GAIÃO, SOUZA e LEÃO, 2012).

Morais e Quintão (2016) indicaram em seu estudo que o número de publicações em CCT, por pesquisadores brasileiros, em periódicos nacionais e estrangeiros, tem crescido substancialmente. O mesmo crescimento pode ser observado em pesquisas de autores brasileiros e estrangeiros, conforme ilustra a Figura 1. 
FIGURA 1

Publicações em Consumer Culture Theory

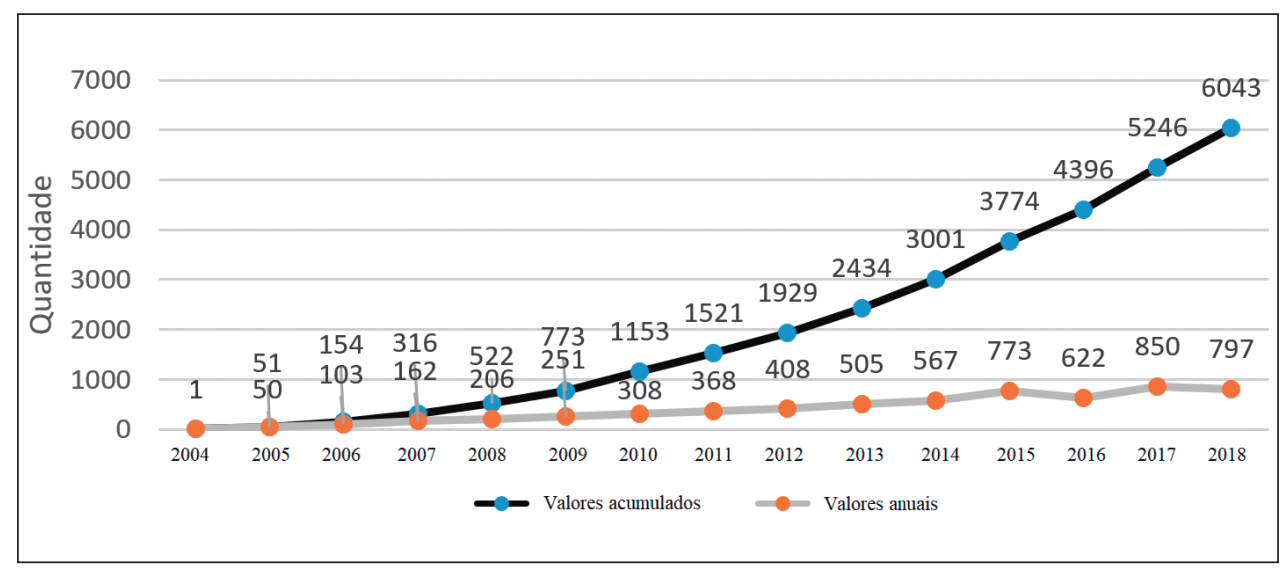

Fonte: Google Scholar.

*Os dados foram coletados de 2004, data da primeira publicação, até a data de 31 de dezembro de 2018.

Os dados apontam que houve um crescimento substancial até 2015 e que em 2016 o número de publicações caiu em aproximadamente $20 \%$, mas voltou a crescer novamente nos anos seguintes, o que em grande parte coaduna com a afirmação de Fitchett, Patsiaouras e Davies (2014) de que a CCT tem sido um assunto emergente e com rápida ascensão. No ano seguinte, voltou a apresentar relevância em publicações nacionais e estrangeiras. A pesquisa foi realizada via Google Scholar, excetuando-se as citações e patentes, pois, a título de comparação, o número de publicações acadêmicas (6043 estudos) é superior ao que foi encontrado na Base de Periódicos da Capes (949 estudos).

Com o crescimento substancial na área, mas ainda com poucos estudos no Brasil, Pinto e Batinga (2018, p. 15) organizaram o livro Cultura e Consumo no Brasil, primeiro livro sobre este assunto, com discussões voltadas para sua história e aplicação no contexto brasileiro em casos que versam sobre falsificação de produtos, funk ostentação, consumo erótico feminino e as representações da família brasileira de baixa renda na mídia. Segundo os autores, é essencial “[...] pensar o consumo quando voltamos o olhar para a nossa relação com os objetos que possuímos ou gostaríamos de possuir". Igualmente, defendem a ideia da não importação pura de teorias estrangeiras, mas sim uma busca de articulação das teorias já existentes com o contexto ao qual estamos inseridos, com nossas culturas e particularidades.

O objetivo do presente artigo, de discutir as críticas, limites e limitações feitas à teoria, bem como os caminhos possíveis dessa abordagem na pesquisa de marketing, especialmente no Brasil, vai ao encontro do que têm buscado os pesquisadores brasileiros que são destaque em CCT no país.

\section{Limites e Limitações à CCT}

Apesar de a CCT, ao longo desses vinte anos, ter tido um crescente reconhecimento da academia, há autores que apontam alguns limites e limitações quanto ao seu uso. 
Askegaard e Linnet (2011, p. 382), por exemplo, mencionam que a própria visão geral oferecida pelo rótulo Consumer Culture Theory tem sido considerada “[...] provocativa por suas omissões e sua tentativa alegada de apresentar uma 'narrativa totalizante' de uma teoria unificada - criticada como uma visão hegemônica de uma grande diversidade e de um campo polifônico de vozes". Contudo os autores chamam atenção para o fato de que, na pesquisa contemporânea do consumidor, benefícios podem ser adquiridos por intermédio da construção de um rótulo específico, desde que seu propósito e seu efeito sejam estabelecer uma plataforma de diálogo inclusivo em vez de guardar um dogma exclusivo.

O estabelecimento de uma base comum para além da afirmação paradigmática solta de que esta pesquisa é "interpretativa" (que pesquisa não é?), e as tentativas de distinguir este grupo de pesquisa (e pesquisadores) de outras comunidades acadêmicas (por exemplo, sociólogos ou antropólogos de consumo), são cruciais para a identificação acadêmica, especialmente de estudantes de doutoramento (ASKEGAARD e LINNET, 2011, p. 382).

Diante dessa crítica, pode-se questionar e problematizar o fato de o próprio nome/rótulo da CCT fazer alusão a uma teoria da cultura do consumidor, e não se tratar de uma teoria única que busca explicar um determinado fenômeno. Da mesma forma, Fitchett, Patsiaouras e Davies (2014) argumentam que as várias comunidades culturais e interpretativistas não necessariamente valorizam uma identidade (individual ou de grupo/comunidades), o que fez o termo ser amplamente utilizado e aceito, funcionando como uma espécie de mito da criação.

Apesar de diversos pesquisadores defenderem o uso do termo, pergunta-se: por que chamar de Consumer Culture Theory se não se trata de uma teoria específica? Por que limitar à palavra theory tantas perspectivas com pontos de interesses tão diversos e distintos? Em lugar de limitar uma subárea tão grande e diversa do comportamento do consumidor ao termo "teoria", a sugestão do presente ensaio teórico é oferecer uma nomenclatura como "abordagem", "corrente" ou "analítica" da cultura do consumo.

Tal questão é problematizada neste artigo, porque se entende que não foi desenvolvida uma teoria única, mas sim uma abordagem, uma analítica sobre a cultura do consumo e sobre o campo do comportamento do consumidor de caráter mais plural, exatamente para fugir de uma construção de uma teoria fechada ou modelo teórico positivista. Igualmente, Fitchett, Patsiaouras e Davies (2014) defendem que a CCT não é uma resposta às mudanças sociais e culturais, mas sim um produto delas; e McCkracken (2007) relembra que o conceito de cultura é considerado um fenômeno. Dessa forma, defende-se a substituição da denominação Teoria da Cultura do Consumidor por Analítica ou Abordagem da Cultura do Consumo.

É possível compreender que a construção do rótulo/marca da CCT tem um sentido importante de identificação acadêmica, como Askegaard e Linnet (2011) sinalizaram, e de criação institucional de um lugar de fala no campo do marketing, porém a crítica do presente ensaio teórico refere-se ao limite que o termo "teoria" impõe ao que a CCT representa. O crescimento de estudos feitos sob tal marca e o avanço que eles têm proporcionado à disciplina do marketing como um todo são visíveis. Contudo a palavra teoria não parece adequada, levando-se em consideração que a CCT 
é conceituada como um campo de investigação com abordagens teóricas e metodológicas para diferentes stakeholders (ARNOULD e THOMPSON, 2015).

Askegaard e Linnet (2011) e Casotti e Suarez (2016) também indicam limitações da pesquisa da CCT por ser focada no indivíduo. Na visão dos autores, a força da CCT, em comparação com as sociologias de consumo, sempre esteve atrelada à inclusão de registros ricos e detalhados de experiências da vida real dos consumidores, como pessoas individuais ou pequenos grupos. Assim, Askegaard e Linnet (2011) sinalizam que isso levou à negligência de elementos (predominantemente sociais) de forças que moldam a vida dos consumidores e não são necessariamente parte de experiências ordinárias de consumo. Ou seja, o foco em experiências vividas não deve conduzir a CCT a repetir as tendências de individualização do restante da comunidade de pesquisa do consumidor:

Experiências são individualizadas, mas o elemento "vivido" chama a nossa atenção para as condições em que essas experiências se desenrolam, condições que não são necessariamente experienciadas por si (ASKEGAARD e LINNET, 2011, p. 397).

McCracken (2007, p. 100) corrobora ao afirmar que o significado cultural deve ser considerado tendo em vista seus três lugares na teoria: “[...] no mundo culturalmente constituído, no bem de consumo e no consumidor individual, movendo-se numa trajetória com dois pontos de transferência: do mundo para o bem e do bem para o indivíduo".

Tendo se originado de um movimento anti-stablishement, a CCT cresceu desenvolvendo aspectos positivos: uma sensibilidade autocrítica e uma vocação reflexiva forte (CASTILHOS, 2015). Aos seus autores, isso tornou possível ter consciência da própria limitação do campo, bem como indicar aspectos que precisam ser melhorados, como foi o caso de Thompson, Arnould e Giesler (2013).

Thompson, Arnould e Giesler (2013, p. 164) criticam a concentração das pesquisas no eixo Europa-América do Norte e afirmam que isso naturaliza e institucionaliza a hegemonia do norte e colabora para o estabelecimento de uma relação centro-periferia, em que o sul estaria em uma posição de “[...] fonte de dados exóticos e como objetos do conhecimento das ciências sociais, ao invés de ser visto como produtor de conhecimento reflexivo sobre sua própria existência, muito menos como provedor de ideias e conceitos que tenham valor para as epistemes do norte". Desse modo, os autores chamam atenção para a necessidade de se ampliarem os trabalhos da CCT aos contextos da América do Sul e veem como uma falha da CCT a omissão de trabalhos de teóricos culturais influentes como o de Néstor García Canclini e o de Epeli Hau'ofa.

Por fim, mas não menos importante, um questionamento comum refere-se ao método utilizado em pesquisas em CCT, com foco predominante em pesquisa qualitativa. A crítica se dá frente à produção de conhecimento com base em poucos dados, o que dificultaria a generalização populacional, mas não teórica; além de uma crítica mais antiga (década de 1980-1990): de que pesquisas interpretativistas geravam resultados rasos frente às descrições e categorizações da realidade social (CASOTTI e SUAREZ, 2016). Além do mais, pesquisas qualitativas podem promover descobertas acidentais (serendipity) (GODOY, 1995). 


\section{A CCT como Caminho para a Pesquisa de Marketing no Contexto Brasileiro}

Mesmo representando uma pluralidade de abordagens teóricas e de objetivos de investigação, os pesquisadores da CCT, contudo, partilham uma orientação teórica comum em relação ao estudo da complexidade da cultura, que liga de forma programática seus respectivos esforços de investigação. Tendo em vista que a CCT busca explorar a distribuição heterogênea de significados e a multiplicidade de grupos culturais que existem dentro do mais amplo quadro sócio-histórico da globalização e do capitalismo de mercado (ARNOULD e THOMPSON, 2005), nota-se que tal tradição teórica pode se configurar um caminho bastante rico para a pesquisa na área de marketing no contexto brasileiro. Ao considerar a complexidade da cultura brasileira e as especificidades do contexto de consumo no Brasil - diferente do consumo em países desenvolvidos -, foi possível perceber que tanto o contexto brasileiro pode agregar muito à CCT, conduzindo a novos fenômenos e novos construtos, quanto pode contribuir com um olhar mais interpretativo e penetrante para a cultura do consumo no país.

Quintão (2018) alerta para o trabalho que vem sendo desenvolvido por Casotti e Ayrosa desde 2009 no intuito de realizarem eventos e coordenarem o caminho de pesquisas, orientações e publicações na área. Para ele, várias universidades brasileiras têm aderido a estudos neste campo do conhecimento, que apresentou uma evolução nos últimos seis anos, com destaque para a região Sudeste - COPPEAD-UFRJ, Unigranrio, ESPM, PUC Minas, PUC Rio, UFF, FGV, UFSJ, IFSP - e também as regiões Sul - com UFRGS, UEM e Univates - e Nordeste - UFPE.

Para Casotti e Suarez (2016), os pesquisadores da CCT no Brasil ainda buscam maior reconhecimento de seus trabalhos no país, já que, no contexto internacional, observa-se a diminuição de resistências, preconceitos e questionamentos sobre a cientificidade dos resultados da pesquisa interpretativa. Em um país com uma cultura tão peculiar e com problemas sociais tão acentuados, seria bastante interessante investigar questões teóricas propostas pela CCT, como experiências de consumo, significados culturais, projetos de identidade dos consumidores, formação do consumo por classe, etnia, gênero e outras habituais categorias sociais; institucionalização e reprodução das relações de poder nas hierarquias socioeconômicas. Pereira e Souza (2018), em seu estudo sobre heterossexismo, consumo, gênero e sexualidade, por exemplo, evidenciam que o significado simbólico de um produto é socialmente construído e que, portanto, o entendimento dessa prática de consumo contribui para a compreensão gerencial do fenômeno.

Esse argumento encontra respaldo, por exemplo, no artigo de Pinto e Freitas (2012, p. 5), no qual apontam uma lista de possibilidades para a "[...] realização de pesquisas que retratem a realidade vivida pelos consumidores" e para o fato de que "[...] ganham espaço também os estudos regionais, nos quais seria possível investigar hábitos, rituais e mitos de consumo de uma infinidade de produtos e serviços, bem como as posses e as experiências que podem ser construídas simbolicamente pelos indivíduos envolvidos".

Castilhos (2015) também enxerga possibilidades de uma contribuição genuinamente brasileira para os debates na CCT. O autor aponta a análise das dinâmicas de mercado no espaço urbano como uma oportunidade para o estabelecimento de uma agenda de estudos sistemática, para a inserção de pesquisadores brasileiros em uma posição de vanguarda na produção de conhecimento no campo da CCT. 
A profunda desigualdade social, que resulta em violência urbana, a presença de uma sociedade ao mesmo tempo extremamente classista e onde os marcadores de pertencimento social nem sempre são explícitos e a existência de uma dinâmica de mobilidade recente se projetam no espaço urbano das grandes cidades brasileiras e fazem delas contextos privilegiados, que exacerbam as características dos fenômenos a serem investigados (CASTILHOS, 2015, p. 162).

A CCT representa, assim, um campo rico de oportunidades de pesquisa para o marketing no Brasil e já vem gradativamente conquistando espaço no país. De acordo com Belk e Casotti (2014), desde a segunda metade dos anos 2000, parece haver uma maior preocupação no Brasil em torno da discussão das características metodológicas do conhecimento científico voltado para o marketing, bem como têm crescido estudos voltados para a cultura do consumo no país. Eles explicam que alguns artigos destacam a predominância do positivismo, mas também há uma constante expansão dos estudos interpretativos na pesquisa de marketing e discussões que exploram diferentes propostas teóricas e métodos de pesquisa qualitativa.

Tais propostas teóricas e contextuais apresentam um nível de diversidade cultural característico do Brasil e que têm consonância com a CCT. Belk e Casotti (2014) citam alguns exemplos de trabalhos já publicados com esse teor, como: estudos sobre consumo e identidade (BARROS, SAUERBRONN, COSTA et al., 2010; BARBOZA e AYROSA, 2013); pesquisas com foco em grupos específicos de consumo que raramente aparecem nos estudos do comportamento do consumidor, como consumidores de baixa renda (PINTO, 2013), homossexuais (PEREIRA e AYROSA, 2012) e pessoas com deficiência (FARIAS e CASOTTI, 2014); e temas mais críticos ao consumo, como resistência ao consumo, abandono de categoria e anticonsumo (SUAREZ, CHAUVELL e CASOTTI, 2012; SUAREZ, 2014).

Dessa forma, Belk e Casotti (2014) afirmam que existem demandas generalizadas para expandir os pontos de vista culturais e históricos da pesquisa na CCT, além da construção de um corpo teórico específico para essa área do conhecimento. Corroborando os argumentos já trazidos pelo presente artigo - de Pinto e Freitas (2012) e Castilhos (2015) -, Belk e Casotti (2014) indicam que, pelo fato de oferecer uma enorme diversidade de contextos históricos, demográficos, econômicos, políticos, religiosos e culturais, a sociedade brasileira pode propiciar um campo bastante rico para a investigação de práticas e expressões de consumo por grupos urbanos, comunidades virtuais e movimentos populares, enriquecendo a pesquisa da CCT.

\section{Considerações finais}

Este artigo teve o objetivo de discutir as possibilidades da Teoria da Cultura do Consumo, as críticas feitas a ela por outros autores e os caminhos possíveis dessa tradição teórica na pesquisa de marketing no Brasil. Concluiu-se que a CCT tem ganhado crescente atenção no campo do comportamento do consumidor, com estudos desenvolvidos em vários sentidos, tais como: padrões sócio-históricos de consumo, culturas de mercado, identidade do consumidor, apropriações do uso de mídias, entre outros.

O mérito deste trabalho está em indicar críticas, limitações e possíveis soluções e questionamentos apontados por alguns autores. As contribuições deste artigo foram formuladas 
visando mais ao melhoramento, refinamento dessa linha de pensamento do que de torná-la sem validade. A principal crítica feita no presente ensaio teórico à CCT foi relativa à nomenclatura "theory" da Consumer Culture Theory, já que se entende que não se trata de uma teoria fechada para explicar um fenômeno único. Ou seja, o termo teoria parece inadequado para referência e a sugestão do presente ensaio teórico é oferecer uma nomenclatura como "abordagem" ou "analítica" da cultura do consumo.

Percebeu-se que a CCT manifesta muitas possibilidades na pesquisa de marketing, principalmente no contexto brasileiro, já que o país apresenta uma cultura rica e diversa no que tange a questões históricas, sociais, econômicas e demográficas, atreladas ao aspecto do consumo. Como sugestão para pesquisas futuras ligadas à CCT no contexto do Brasil, podem ser apontados estudos referentes a experiências com novos arranjos familiares, experiências relativas a etnia, experiências de não consumo, resistência ao consumo ou abandono de categoria e experiências vividas por classes sócio-econômicas.

Por exemplo, é possível afirmar que o tema "experiências vividas por classes sócioeconômicas" pode se inserir em diversas vertentes de interesse da CCT, tais como culturas de mercado, padrões sócio-históricos de consumo, projetos de identidade do consumidor, significados de consumo e dimensões das experiências de consumo. Assim, existem caminhos na CCT em que é possível explorar a questão da cultura do consumo atrelada às experiências vivenciadas por diferentes classes socioeconômicas, que vão desde o consumo de produtos e serviços de luxo por classes mais abastadas até o consumo da classe $C$ ou da população de baixa renda.

Sugere-se, ainda, para estudos futuros relacionados à CCT no Brasil, que os pesquisadores de marketing não se limitem apenas a referenciar e importar a bibliografia da CCT internacional como base teórica, mas sim ousem e deem atenção a autores importantes e clássicos do Brasil de áreas como Antropologia, Sociologia e História. Os trabalhos de diversos autores brasileiros podem muito contribuir para a compreensão da cultura de consumo existente no Brasil e em suas diversas regiões.

Por exemplo, o antropólogo Darcy Ribeiro (1995), em sua obra intitulada O Povo Brasileiro, abordou a formação de nosso povo, suas matizes culturais e étnicas, a miscigenação enquanto característica marcante do país e a estratificação das classes sociais. O sociólogo Gilberto Freyre (1997), por sua vez, em sua obra Casa-Grande \& Senzala, também abordou a formação sociocultural brasileira e a miscigenação, destacando a importância da casa-grande (casa da família do dono das propriedades rurais do Brasil colonial) e da senzala (alojamentos que correspondiam à moradia dos escravos), que, na visão do autor, se complementaram na constituição do povo brasileiro. Tais obras podem contribuir para os estudos sobre consumo no Brasil, na medida em que proporcionam uma reflexão sobre a formação da cultura brasileira e podem colaborar para a compreensão sobre os rituais e os comportamentos de consumo da(s) sociedade(s) brasileira(s), que podem ter raízes históricas e diferenças regionais e identitárias.

Assim, uma possível pergunta para os investigadores é: o que os trabalhos de Ribeiro (1995) e Freyre (1981) podem dizer e ajudar a refletir sobre a cultura de consumo do Brasil? Atentarse a isso pode colaborar para o desenvolvimento de estudos que revelem sobre as culturas de consumo dos diversos Brasis existentes nesse imenso país e suas raízes históricas e socioculturais. 


\section{Referências}

AGUIAR, E. C.; FARIAS, S. A. Estímulos sensoriais e seus significados para o consumidor: investigando uma atmosfera de serviço centrado na experiência. Revista Brasileira de Marketing, v. 13, n. 5, p. 65-77, 2014.

AlmeIDA, M. R. C.; FROEMMING, L. M. S.; HUBER, C. M. Experiência de Compra no Ponto de Venda em Lojas de Varejo de Panifício. Revista de Administração IMED, v. 3, n. 3, p. 209-220, 2013.

ARNOULD, E. J. Consumer culture theory: retrospect and prospect. European Advances in Consumer Research, v. 7, n. 1, p. 605-607, 2006.

ARNOULD, E.J.; THOMPSON, C.J. Consumer culture theory (CCT): twenty years of research. Journal of Consumer Research, v. 31, n. 4, p. 868-882, 2005.

ARNOULD, E. J.; THOMPSON, C. J. Consumer Culture Theory: Ten years gone (and beyond). In: THYRAFF, A.; MURRAY, J. B.; BELK, R.W. (Org.). Research in consumer behavior. Bingley, UK: Emerald Group Publishing, 2015. p. 1-21.

ARNOULD, E. J.; PRICE, L. River Magic: Extraordinary experience and the extended service encounter. Journal of Consumer Research, v. 20, n. 1, p. 24-45, 1993.

ASKEGAARD, S.; LINNET, J. P. Towards an Epistemology of Consumer Culture Theory: Phenomenology and the context of context. Marketing Theory, v. 11, n. 4, p. 381-404, 2011.

BALDANZA, R. F.; ABREU, N. R. Reflexões sobre as influências da indústria cultural na difusão de valores estéticos: a TV aberta brasileira e a padronização da beleza. Mediaciones Sociales, v. 7, p. 91-110, 2010.

BARBOZA, R. A.; AYROSA, E. A. Um estudo empírico sobre a construção da identidade social do consumidor de Toy Art. Revista de Ciências da Administração, v, 1, n. 1, p. 11-21, 2013.

BARROS, D. F. et al. Download, pirataria e resistência: uma investigação sobre o consumidor de música digital. Comunicação, Mídia e Consumo, v. 7, n. 18, p. 125-151, 2010.

BARROS, C. Luz, Câmera... Inanição!: os caminhos do consumo em um seriado sobre dois mundos. PragMATIZES-Revista Latino-Americana de Estudos em Cultura, v. 4, n. 6, p. 72-84, 2014.

BELK, R.; YEH, J. H. Tourist photographs: signs of self. International Journal of Culture, Tourism and Hospitality Research, v. 5, n. 4, p. 345-353, 2011.

BELK, R. W. Extended self in a digital world. Journal of Consumer Research, v. 40, n. 3, p. 477-500, 2013.

BELK, R.; CASOTTI, L. M. Ethnographic research in marketing: past, present, and possible futures. Revista Brasileira de Marketing, v. 13, n. 6, p. 1-17, 2014.

BELK, R. W. The labors of the Odysseans and the legacy of the Odyssey. Journal of Historical Research in Marketing, v. 6, n. 3, p. 379-404, 2014.

BREI, V. A.; GARCIA, L. B.; STREHLAU, S. A influência do marketing na erotização precoce infantil feminina. TPA-Teoria e Prática em Administração, v. 1, n. 1, p. 97-116, 2012. 
CARVALHO, J. L. F. D. S. D.; MOTTA, P. C. A iluminação ambiental vista pelos participantes das interações de serviços. GESTÃO. Org-Revista Eletrônica de Gestão Organizacional, v. 2, n. 1, p. 19-34, 2004.

CASOTTI, L. M.; SUAREZ, M. C. Dez anos de Consumer Culture Theory: delimitações e aberturas. Revista de Administração de Empresas, v. 56, n. 3, p. 353-359, 2016.

CASTILHOS, R. Dinâmicas de Mercado no Espaço Urbano: lógica teórica e agenda de pesquisa. Revista Brasileira de Marketing, v. 14, n. 2, p. 154-165, 2015.

CEGLIA, D.; OLIVEIRA LIMA, S. H.; LEOCÁDIO, Á. L. An alternative theoretical discussion on crosscultural sustainable consumption. Sustainable Development, v. 23, n. 6, p. 414-424, 2015.

CELSI, R. L.; ROSE, R. L.; LEIGH, T. W. An exploration of high-risk leisure consumption through skydiving. Journal of consumer research, v. 20, n. 1, p. 1-23, 1993.

COSKUNER-BALLI, G. Market practices of legitimization: Insights from Consumer Culture Theory. Marketing Theory, v. 13, n. 2, p. 193-211, 2013.

COVA, B.; COVA, V. CCT applied research and the limits of consumers' heroicisation. Journal of Marketing Management, v. 30, n. 11-12, p. 1086-1100, 2014.

CRUZ, Z. G. et al. O processo de transferência de significados: um estudo sobre o consumo simbólico de lingerie por mulheres de baixa renda. Comunicação Mídia e Consumo, v. 9, n. 25, p. 141-178, 2012.

CUPOLILLO, F. B. N.; AYROSA, E. A. T. Reflexões sobre consumo, identidade e masculinidade em um bairro carioca. Revista Interdisciplinar de Marketing, v. 5, n. 2, p. 19-33, 2016.

DAlMORO, M.; PEÑAlOZA, L.; NIQUE, W. M. Resistência do Consumidor: Diferentes Estágios Teóricos de um mesmo Conceito. Revista Brasileira de Marketing, v. 13, n. 1, p. 119-132, 2014.

FABI, M. J. S.; LOURENÇO, C. D. S.; SILVA, S. S.; SETTE, R. S. Consumo consciente: a atitude do cliente perante o comportamento socioambiental empresarial. Revista Symposium (Lavras), v. 7, p. 104-127, 2009.

FARIA, M. D.; CASOTTI, L. M. Representações e estereótipos das pessoas com deficiência como consumidoras: o drama dos personagens com deficiência nas telenovelas brasileiras. Organizações \& Sociedade, v. 21, n. 70, p. 387-404, 2014.

FARIAS, S. A.; AGUIAR, E. C.; MELO, F. V. S. Store atmospherics and experiential marketing: A conceptual framework and research propositions for an extraordinary customer experience. International Business Research, v. 7, n. 2, p. 87, 2014.

FITCHETT, J. A.; PATSIAOURAS, G.; DAVIES, A. Myth and ideology in Consumer Culture Theory. Marketing Theory, v. 14, n. 4, p. 495-506, 2014.

FREYRE, G. Casa grande e senzala: formação da família brasileira sob o regime de economia patriarcal. Rio de Janeiro: Record, 1997.

GAIÃO, B. F. S.; SOUZA, I. L.; LEÃO, A. L. M. S. Consumer Culture Theory (CCT) já é uma escola de pensamento em marketing? Revista de Administração de Empresas, v. 52, n. 3, p. 330-344, 2012.

GODOY, A. S. Pesquisa Qualitativa: tipos fundamentais. Revista de Administração de Empresas, v. 35, n. 3, p. 20-29, 1995. 
GOPALDAS, A. Marketplace sentiments. Journal of Consumer Research, v. 41, n. 4, p. 995-1014, 2014.

HENKES, L.; DALMORO, M. Mulheres ricas: distinção e subjetivação nas práticas de consumo da classe A. Revista Interdisciplinar de Marketing, v. 5, n. 2, p. 34-48, 2016.

HIRSCHMAN, E.; THOMPSON, C. J. Why media matter: towards a richer understanding of consumers'relationships with advertising and mass media. Journal of Advertising, v. 26, n. 1, p. 43-60, 1997.

HOLBROOK, M. B.; HIRSCHMAN, E. C. The experiential aspects of consumption: consumer fantasies, feelings, and fun. Journal of Consumer Research, v. 9, n. 2, p. 132-140, 1982.

IZBERK-BILGIN, E. Infidel brands: unveiling alternative meanings of global brands at the nexus of globalization, consumer culture, and Islamism. Journal of Consumer Research, v. 39, n. 4, p. 663-687, 2012.

JOY, A.; L. I., E. P. H. Studying consumption behaviour through multiple lenses: an overview of Consumer Culture Theory. Journal of Business Anthropology, v. 1, n. 1, p. 141-73, 2012.

KOZINETS, R. V. Utopian enterprise: Articulating the meanings of Star Trek's culture of consumption. Journal of consumer research, v. 28, n. 1, p. 67-88, 2001.

KOZINETS, R. V.; HANDELMAN, J. M. Adversaries of consumption: Consumer movements, activism, and ideology. Journal of consumer research, v. 31, n. 3, p. 691-704, 2004.

KOZINETS, R. V. Click to connect: netnography and tribal advertising. Journal of advertising research, v. 46, n. 3, p. 279-288, 2006.

KRAEMER, F.; SILVEIRA, T.; ROSSI, C. A. V. Evidências cotidianas de resistência ao consumo como práticas individuais na busca pelo desenvolvimento sustentável. Cadernos EBAPE.BR, v. 10, n. 3, p. 677-700, 2012.

LAWRENCE, T. B.; PHILLIPS, N. Understanding cultural industries. Journal of Management Inquiry, v. 11, n. 4, p. 430-41, 2002.

LEÃO, A. L. M.; VIEIRA, R. S. G.; GAIÃO, B. F. Proposição tipológica de perfis de consumidores de vinhos baseada em valores humanos. Revista Economia \& Gestão, v. 11, n. 26, p. 8-32, 2011.

LEVY, S. History of qualitative research methods in marketing. In: BELK, R. (Ed.). Handbook of Qualitative Research Methods in Marketing. Cheltenham, UK: Edward Elgar, 2006. p. 3-16.

MCCRACKEN, G. Cultura e Consumo: uma explicação teórica da estrutura e do movimento do significado cultural dos bens de consumo. RAE-Clássicos, Revista de Administração de Empresas, v. 47, n. 1, p. 99-115, mar. 2007.

MORAIS, I. C.; QUINTÃO, R. T. Reflexões sobre o campo de pesquisa da Consumer Culture Theory no Brasil. In: LATIN AMERICAN RETAIL CONFERENCE, 9., 2016, São Paulo. Anais... São Paulo: CLAV, 2016. Disponível em: <https://www.bibliotecadigital.fgv.br/ocs/index.php/clav/clav2016/paper/ download/5895/1683>. Acesso em: 13 mar. 2019.

PAIVA, M. B. M. et al. O consumo de luxo: um estudo sobre valores e significados no consumo de bolsas por mulheres brasileiras. FFBusiness, v. 7, p. 93-108, 2010. 
PEÑALOZA, L.; BARNHART, M. Living U.S. Capitalism: The Normalization of Credit/Debt. Journal of Consumer Research, v. 38, n. 4, 2011.

PEÑALOZA, L.; MISH, J. The nature and processes of market co-creation in triple bottom line firms: Leveraging insights from consumer culture theory and service dominant logic. Marketing Theory, v. 11, n. 1, p. 9-34, 2011.

PEÑALOZA, L.; PRICE, L. Consumer resistance: a conceptual overview. Advances in Consumer Research, v. 20, n. 1, p. 123-128, 1993.

PEREIRA, S. J. N.; AYROSA, E. A. T. Between two worlds: on ethnographic study of gay consumer culture in Rio de Janeiro. BAR, v. 9, n. 2, p. 211-228, 2012.

PEREIRA, S. J. N.; SOUZA, E. M. Azul para os meninos, Rosa para as meninas: Heterossexismo, consumo, gênero e sexualidade. In: PINTO, M. R.; BATINGA, G. L. (Org.). Cultura e Consumo no Brasil: estado atual e novas perspectivas. Belo Horizonte: PUC Minas, 2018. p. 83-101.

PINTO, D. C. et al. Online identity construction: How gamers redefine their identity in experiential communities. Journal of Consumer Behaviour, v. 14, n. 6, p. 399-409, 2015.

PINTO, M. R. As experiências de consumo de eletrônicos de consumidores de baixa renda no Brasil. Revista Brasileira de Marketing, v. 12, n. 1, p. 166-195, 2013.

PINTO, M. R.; BATINGA, G. L. Cultura e Consumo no Brasil: estado atual e novas perspectivas. Belo Horizonte: PUC Minas, 2018.

PINTO, M. R. et al. Consumer Culture Theory (CCT) no contexto das experiências de consumo de serviços: em busca de uma agenda de pesquisa. RIMAR, v. 5, n. 2, p. 49-68, jul./dez. 2015.

PINTO, M. R.; FREITAS, R. C. A Teoria da Cultura do Consumo no contexto das experiências de consumo de serviços: discussões e questões para um campo ainda inexplorado para pesquisas. In: SEMINÁRIOS EM ADMINISTRAÇÃO (SEMEAD), 15., São Paulo. Anais... São Paulo: USP, 2012.

QUINTÃO, R. T. O campo de pesquisa da cultura de consumo no Brasil. In: PINTO, M. R.; BATINGA, G. L. (Org.). Cultura e Consumo no Brasil: estado atual e novas perspectivas. Belo Horizonte: PUC Minas, 2008. p. 83-101.

RIBEIRO, D. O povo brasileiro: evolução e o sentido do Brasil. São Paulo: Companhia das Letras, 1995. $476 \mathrm{p}$.

ROHDEN, S. F. et al. Consumo colaborativo: economia, modismo ou revolução?. Desenvolve: revista de gestão do Unilasalle, Canoa, v. 4, n. 2, p. 9-24, jul. 2015.

SUAREZ, M. C.; CHAUVELL, M. A.; CASOTTI, L. M. Motivações e significados do abandono de categoria: aprendizado a partir da investigação com ex-fumantes e ex-proprietários de automóveis. Cadernos EBAPE.BR, Rio de Janeiro, v. 10, n. 2, p. 412-434, jun. 2012.

SUAREZ, M. C. Meanings of consumption and abandonment: understanding smoking cessation symbolism. BAR, v. 11, n. 2, p. 210-227, 2014.

THOMPSON, C. J.; ARNOULD, E.; GIESLER, M. Discursivity, difference, and disruption: genealogical reflections on the consumer culture theory heteroglossia. Marketing Theory, v. 13, n. 2, p. 1-27, 2013. 
THOMPSON, C. J. Research Frontiers in Research Frontiers in Consumer Culture Theory. 2004. Disponível em: <http://ww.w.acrwebsite.org/presentations/Eric\%20Arnould.pdf>. Acesso em: 13 mar. 2019.

ZHAO, X.; BELK, R. W. Politicizing consumer culture: Advertising's appropriation of political ideology in China’s social transition. Journal of Consumer Research, v. 35, n. 2, p. 231-244, 2008.

\section{LUCIANA ALVES RODAS VERA}

ORCID: http://orcid.org/0000-0001-6043-3252

Doutora em Administração pela Universidade Federal de Minas Gerais (UFMG); Professora na Universidade Salvador (Unifacs), Salvador - BA, Brasil. E-mail: lu.alvesvera@gmail.com

\section{MARLUSA DE SEVILHA GOSLING}

ORCID: http://orcid.org/0000-0002-7674-2866

Doutora em Administração pela Universidade Federal de Minas Gerais (UFMG); Professora na Universidade Federal de Minas Gerais (UFMG), Belo Horizonte - MG, Brasil. E-mail: marlusa@ufmg.br

\section{HELENA BELINTANI SHIGAKI}

ORCID: http://orcid.org/0000-0003-0456-7146

Doutoranda em Administração pela Universidade Federal de Minas Gerais (UFMG).

E-mail: belintanihs@gmail.com 